\title{
The Mobilisation OF RACE AND GENDER ON AN INTERNET MAILING LIST, V1.0
}

\author{
Transforming Cultures eJournal, \\ Vol. 2 No 2, December 2007 \\ http://epress.lib.uts.edu.au/journals/TfC
}

\section{Jonathan Paul Marshall ${ }^{1}$}

\begin{abstract}
This paper explores an incident in which race and gender categories were mobilised on the Internet Mailing List Cybermind during an incident of conflict. The people on this Mailing List would resist easy classification as 'racist', yet race proved an issue of fracture, while gender appeared to function as a way of universalising sameness and attempting integration. The process of cultural construction is shown to involve the rhetorical deployment of categories, and deployment of these categories often makes sites of 'expertise', which become justifiers and motivators of behaviour. This suggests that cultural barriers are not so much latent but created in response to crisis and debate. Competitions between multiple viewpoints, uneasy truce, or resolution by departure, are all hallmarks of Mailing List life.
\end{abstract}

\section{Introduction}

Race, gender and nationality form categories for social organisation, inequality and discrimination in the offline world, but it has frequently been held that such offline categories will have less effect online because they are largely invisible. For example Baldwin and Flood write: “we cannot prejudice our interlocutor's words consciously or even unconsciously based upon powerful cultural stereotypes conveyed through visual media" 2 . Poster argues that people online cannot attach to "the fixed shapes of historic ethnicity"3, while ignoring the question of whether ethnicity has ever had a fixed

\footnotetext{
${ }^{1}$ During the period in which this paper was written the author was an ARC Research Fellow at the University of Technology Sydney.

${ }^{2}$ B. Baldwin, B. \& T. Flood, "Introduction: to Rhetorical Dimensions of Cyberspace", RhetNet. 1997 $<\mathrm{http}: / /$ wac.colostate.edu/rhetnet/rdc/edintro.html $>$

${ }^{3}$ Mark Poster, "Virtual Ethnicity: Tribal Identity in an Age of Global Communications", in Steve Jones (ed) Cybersociety 2.0, Thousand Oaks, Sage, 1998, p.208.
} 
shape $^{4}$. Such positions imply that if people are not aware of race or gender then there will be no racial or gender problems. This position is not as common in academic analysis as it once was, but still may be found among Internet users ${ }^{5}$. However, academics may still hold that the Internet is a liminal space in which roles collide, vary and are transformed ${ }^{6}$ while other work shows that the Internet may be used to intensify ethnicity, diasporic identity, racial supremacy, or gender identity ${ }^{7}$.

This paper continues the move to show that the dynamics of offline ideologies, racial discrimination, and rhetorics are not immediately shed online, by exploring the intersection of race and gender categories (and the ways they are used to shape behaviour) on the Mailing List Cybermind.

I have been openly conducting research on this Mailing List from mid-1995 to the end of 2007 and have been on the List since December 1994. My main methods of research have involved participatory ethnographic fieldwork, study of archival transcripts, onlist surveys, open interviews, and offlist interviews through email, face to face and over the telephone. List members have been remarkably open to this process, and issues around the research have been discussed many times on the List. List members have been asked to read and comment upon my writings about Cybermind, and were invited to comment on early drafts of this paper, as they are invited to comment upon this whole journal issue for inclusion in the comments section. List members have also contributed to this journal issue. Apart from self-imposed censorship on occasions in which my opinions may prove hurtful to individuals who have been friendly and co-operative, there have been no restrictions on my writing, and there has been nothing important which I could not discuss. However, this article has only been published when anonymity could be

\footnotetext{
${ }^{4}$ Thomas Holt The Problem of Race in the 21st century, Harvard. 2000, p 47.

5 For some criticisms of 'erasism', or the removal of race and gender, see Eleanor Russel Mason, "Resisting Erase-ism”, Brillo No.3, 1997, <http:/www.brillomag.net/No3/erasism.htm>. See also Jerry Krang, Jerry "Ruminations on cyber-race", in Dissent, 50(2), 2003, pp.58-63 and MC. Bowen, \& Kali Tal (nd) "interview with Kali tal: Re: boohabian texts", <http://www.mdcbowen.org/p2/boo/kalis.htm>

${ }^{6}$ Lisa Nakamura Cybertypes: Race Ethnicity and Identity on the Internet, Routledge, London, 2002.

${ }^{7}$ For reinforcing diasporic identity see Daniel Miller, Daniel \& Don Slater The Internet: An Ethnographic Approach, Berg, Oxford, 2000. Promotion of racial supremacy is discussed by Les Back "Aryans reading Adorno: cyber-culture and twenty-first century racism" in Ethnic and Racial Studies, 25(4), 2002: 62851. Milne's paper in this issue gives a good summary of work which suggests that categories like gender may even become more pronounced online than off.
} 
preserved as much as possible ${ }^{8}$. During the period of the case study I was ill and did not make any significant, or acknowledged, contributions to the events. Archives of the discussion no longer exist and the records are taken from my personal copies of the mail.

The aim of the paper is to discover some of the circumstances which increase the relevance of race and gender categories, and to show how these categories can intensify even when people are denying their effect. The case is more interesting because Cybermind is a List with marked anti-racist behaviour and ideology, and arguments that most members were ongoingly, or particularly, racist would be hard to prove. It has had members of many different ethnic identifications without race becoming a divisive issue before the events described in this paper. I hope to show that this particular response to race was created at a particular time, rather than was the only response possible. As a result, the presentation proceeds via historical sequence, rather than by gathering types of incidents to illustrate a point, because the historical trajectory seems to have led to particular responses becoming more likely.

\section{Culture, Category and Rhetoric}

Life in a Mailing List can often seem a heightened experience like a drama or a soap opera. Much of the supposedly humdrum routine of life is deleted or not mentioned, emotions seem more intense, and members are faced with a series of questions, expectations, or even dreads. What moves will other List members make? Can productive harmony be maintained? Will the List burst into flame changing things forever? Will the List maintain interest and continue to be worth persevering with? Such a life can be overwhelming, tedious and suspenseful, all at the same time, and analysis, to be realistic, should convey some of the sense of self-determination and precariousness felt by List members.

In such a world, culture is like a rhetorical process creating the grounds of its own being. It is contested, and largely up for grabs. To those involved the struggles can be involving and exciting. To others they can be boring or painful. However, those who persuade others of the nature of their common culture, the social and self categories

\footnotetext{
${ }^{8}$ Discussion about the problems of online ethnography can be found in the introduction to Marshall (2007) and more briefly in the introduction to this journal.
} 
involved and the borders of those categories, may have some temporary control over that culture. With repetition they can solidify it, at least until the next competition. These struggles are often maintained until those resisting, what becomes the dominant culture, decide to leave.

Power ratios are enfolded in the establishment of knowledge and expertise, because power is about persuasion and getting someone to do something or to acknowledge another's superiority. Superior power enables persuasion and persuasion gives some kind of power - even if temporary. This is not to argue against the power/stupidity nexus, or to suggest that the powerful know what they are doing or are better informed than others, but simply to suggest that power is related to convincing others and to being able to state positions which others are more likely to acquiesce to. However the power of persuasion is limited by its tools and by the ways that communication is structured and disseminated. The means to persuade, as well as enabling persuasion, limit the possibilities of persuasion. Mailing List organisation gives certain people, such as the moderators, greater freedom to act and restrict others, than is granted to other List members, so that not all members are equal, but no members have to agree at cost of their lives or principles; they may always move elsewhere.

One of the main tools of persuasion is language and the grouping of objects and people within linguistic categories. This grouping seems to be of fundamental rhetorical importance. Categories do not group 'things' which are all the same in the same way'. The referents of a category may differ in many ways, be similar in many different ways, and may depend on context, so that the positioning of things 'within' a category may be fluid and contested. When grouped, certain members of the category act as good examples (or 'prototypes'). With social groups these prototypes tend to be normative, so that members may try to emulate the prototype of their category. The more features a person or thing appears to share (or can be made to appear to share), with the prototype of their category the more they will be seen to exemplify that category, for good or bad. Importantly, prototypes seen from outside the category may differ from those seen from within the category. Identifying, or creating, social categories and then putting someone, or some process, into a particular category or attempting to get it to match a prototype,

\footnotetext{
${ }^{9}$ John Taylor Linguistic Categorization: Prototypes in Linguistic Theory, OUP 1989. I am using the term 'thing' loosely not just to refer to nouns but to events and so on.
} 
is a major part of cultural struggle ${ }^{10}$. It is one of the ways voices do not attain the same right to be heard or have the same value attributed to their words.

Categories also seem to have inherent effects on thinking, no matter what the categories pertain to, and no matter how unclear those categories are. For example, the persuasiveness of an argument increases if that argument can be assigned to a prototype of a group with which a person self-categorizes, and people tend to perceive the bad features of their category as universal and the good features as unique. Similarly the persuasiveness of an argument decreases if it can be made to seem prototypic of a social outgroup, and the agreed bad features of that group (by outsiders) are taken as prototypic of all members of that group ${ }^{11}$.

Within this framework Elias and Scotson's formulations about 'established and outsider relations' are important ${ }^{12}$. The 'established', are an already existing group-category, with greater access to social institutions and considerably better networks for promulgating communication than the 'outsiders' who are often newer members. The established have built up networks of support for each other and obligation over time and are relatively unlikely to attack each other in favour of outsiders. Out-group members are less attractive the more they can be perceived as prototypic of a negative out-group $^{13}$. Elias writes:

\footnotetext{
${ }^{10}$ In the paper "Cyberspace or Cybertopos: The creation of online space", Social Analysis 45(1), 2001: 81-102, I argued that the sense of internet space, or online space, gains some of its power through its use as a persuasive tool.

${ }^{11}$ The theory of categories used here, which depends largely on the ideas of Wittegenstein, Vygotsky and Rosch, is outlined in detail in Chapter 1 of Jonathan Marshall Living on Cybermind: Categories, Communication and Control, Peter Lang, NY, 2007. The basic theory of self-categorisation is elaborated in John Turner, M. Hogg, P. Oaks, S. Reicher \& M. Wetherall Rediscovering the Social Group: A Self Categorization Theory, Blackwell, Oxford 1988. The enhancement of persuasion by ingroup allocation is described in Turner et al (1988: 27-8, 154, 160), S.A. Haslam, C. McGarty \& J.C. Turner (1996) "Salient Group Memberships and Persuasion: the Role of Social Identity in the Validation of Beliefs", in J.L. Nye \& A.M. Brower (eds.) What's Social about Social Cognition? Research on Socially Shared Cognition in Small Groups, Sage, Thousand Oaks 1996. and D. Van Knippenberg, N. Lossie \& H. Wilke "In-Group Prototypicality and Persuasion: Determinants of Heuristic and Systematic Message Processing", British Journal of Social Psychology, Vol.33, No.3, 1994: 289-300. M. Biernat, T.K. Vescio \& M.L. Green describe how some people embrace positive stereotypes as highly self descriptive and negative stereotypes as general in their paper "Selective Self-Stereotyping", Journal of Personality and Social Psychology, 71(6), 1996: 1194-1209. Pierre Van den Burgh in "Rehabilitating Stereotypes" in Ethnic and Racial Studies, 20(1), 1997 suggests that stereotyping is best seen as a form of category based behaviour which allows the (over) generalisation of often prudent information, which can become self reinforcing.

${ }^{12}$ Norbert Elias \& John Scotson The Established and the Outsiders (2 ${ }^{\text {nd }}$ Edition), Sage Publishers, Thousand Oaks, 1994.

${ }^{13}$ Elias \& Scotson 1994: 60.
} 
an established group tends to attribute to its outsider group as a whole, the 'bad' characteristics of that group's 'worst' section... In contrast, the self image of the established group tends to be modelled upon its most exemplary, most 'nomic', or norm setting section ${ }^{14}$.

This leads people to have lesser sensitivity to the bad behaviour of fellow insiders and more sensitivity to the behaviour of outsiders. It may also lead some people to have shifting roles depending on their position as exemplars within an argument. Categories are not given but are dynamic. In the case discussed here, the established are also in the majority and most of the main actors had known each other for over 5 years - which is a significant time on an internet based group in this period of internet history.

Whether established or outsider, prototypes stand for the whole of a category; increasing the perception of differences between categories which might have otherwise seemed relatively minor, or at least no greater than differences within the category. As shall be seen, the 'rudeness' of established List members was invisible to other established members, and the messages of the newcomers were interpreted in terms of a 'pre-existent agenda' which was set up by reference to politics external to the List, and used to make the issues seem external to the List. One outsider may even have accepted the classification and taken on the properties of the 'disreputable' prototype and exaggerated it, thus providing the apparent chaos which reinforced the division and made it more real. Sometimes social order depends for its legitimacy on the chaos it creates.

Hopkins \& Reicher show how effective persuaders offline define category boundaries so as to include as many of the audience as possible; try to make the audience and speaker part of a common category; construct the recommended actions or beliefs as congruent, or prototypic, with this category; and try to make opposing arguments represent an outgroup category ${ }^{15}$. Similar processes occur online and thus external categories which are effective offline will continue to have their rhetorical effect deployed online.

\footnotetext{
${ }^{14}$ Ibid: xix

${ }^{15}$ Nick Hopkins \& Steve Reicher "Social Movement Rhetoric and the Social Psychology of Collective Action: a case study of anti-abortion mobilization", Human Relations, 50(3), 1997: 261-87. Hopkins has extended the ideas in Nick Hopkins \& Christopher Moore, "Categorizing the Neighbors: Identity, Distance and Stereotyping”, Social Psychology Quarterly, 64(3), 2001: 239-52, and Vered Kahani-
} 
These arguments are not intended to imply that everything is voluntaristic online. The properties of categories and the structures of communication have effects, whether intended or not. The actions and reactions of others impede any absolute freedom and criticism and responsiveness is influenced by trajectories of events. Organisation of communication gives some players more power and freedom to act than others. Furthermore, particular frames, metaphors and clichés can seem to possess people, so that they literally cannot hear others, and largely seem unable to help but manifest, or be vulnerable to, certain types of arguments, or to make certain types of arguments. People also may be more or less skilled in using such techniques but we should not assume that they are completely in charge of what they are doing. Finally ambiguity is an essential part of the messages and resolution of their meaning may overpower any intention in the author, even if that author restates their intention.

As we shall see, whatever the ideology which is proclaimed, this process of categorisation means that not all voices are equal online. Some can disqualify themselves by protesting against dominant voices - even if their argument supports normally common points of view, in this case an ideology of anti-racism. Online voices can be fragile: ignoring a voice can cause it to die, echoing a voice causes it to have power.

\section{Brief note on 'Race' in the USA}

Racial categories structure much of life in the USA, and often seem to do so according to a polarity of 'black' and 'white' (irrespective of the recognition of people of Hispanic, Asian or Native American descent $)^{16}$. According to Steinhorn and DiggesBrown $^{17}$, Americans segregate themselves by categories of belonging to a race. People live in different areas by race (30-42), they go to different schools (42-51), go to different places of work (55-61), have different places of worship (61-4), go on holiday to different places (67-8), are increasingly playing different sports (68-74), watch different movies, TV programmes and read different magazines (79-87). They have few

Hopkins \& Nick Hopkins (2002) "Representing British Muslims: the strategic dimension to identity construction", Ethnic and Racial Studies, 25(2), 2002: 288-309.

\footnotetext{
${ }^{16}$ It has been suggested to me that this is primarily a US East coast structuration, and that the polarity is less in evidence on the US west Coast. Whether this is true or not, it was the polarity invoked in the series of events to be described below.

${ }^{17}$ Leonard Steinhorn \& Barbara Diggs-Brown By the Color of our Skin: the Illusion of Integration and the Reality of Race, Dutton, NY, 1999
} 
interracial contacts, especially close ones, interracial marriages are rare (21-23), and so on. Whites move out of areas as blacks move in. Upper-middle class blacks create their own enclaves. Both black and white people participate in this separation (perhaps for different reasons), although the other 'races' tend to integrate (17-18).

This racial separation comes together with (and is probably reinforced by), racial stratification. Black men consistently earn less than white men in all educational and work brackets (although they earn more than white women), black men form an exceedingly high proportion of prison inmates, whites still tend to have positions of power in companies and political organisations, health care for blacks is significantly worse, life expectancy is lower, and there is a sense of constant rejection by whites ${ }^{18}$.

However, polls apparently show that white people overwhelmingly reject explicit racism, and say they would work towards ending racism ${ }^{19}$. This joins with a widespread move explaining racial stratification as not resulting from white racism but from the failure of black individuals to take advantage of the free market system, or of having a 'bad culture ${ }^{20}$. Sociologist David Harris, for example, has tried to explain that whites leave areas into which blacks are moving and don't move into black areas, not because of their racism but because they avoid areas with higher poverty rates, declining property values and lower services i.e. supposedly not because of blacks but "because of characteristics associated with being black" ${ }^{21}$. However, this argument can only work and be chosen as a strategy because of racial stratification and discrimination, and it also maintains that stratification and that category separation. At the least these general positions do not challenge the informal means by which the stratification is maintained and do not allow people to draw attention to race issues without being accused of reverse racism $^{22}$. Furthermore, the advantages of the white racial category may be

\footnotetext{
${ }^{18}$ Michael K Brown et al White Washing Race: The Myth of a Color-Blind Society, University of California Press, 2003. For slightly more recent figures see Time Almanac 2006, Information Please, Boston 2005: 375, 390, 137. This does not mean that all people are equally disadvantaged or advantaged by 'colour', but that the prototypes of those categories are (depending on who is viewing them).

${ }^{19}$ Steinhorn \& Diggs-Brown (1999: 10).

${ }^{20}$ Brown et al (2003: 1-13, 15-17), Eduardo Bonilla-Silva Racism Without Racists: Color-Blind Racism and the Persistence of Racial Inequality in the United States, Rowman \& Littlefield, NY, 2003.

21 David Harris "Property values drop when Blacks move in because...: Racial and socioeconomic determinants of neighborhood desirability", American Sociological Review, 64(3), 1999: 461-479.

${ }^{22}$ See the brief discussion on the similar problems with drawing attention to gender at the same time as criticising sexism, in the introduction to this journal.
} 
invisible to people classified as 'white' and it may even be seen as a liability in terms of their cultural position ${ }^{23}$.

Stratification also affects computer ownership and internet participation. Jayajit Chakraborty and M. Martin Bosman show that distribution of PC ownership by race categories varies through out the US:

White households are significantly more likely to own a PC than African American households in all regions. The extent of this racial divide is greatest in the Midwest and smallest in the West, and particularly high in the $\$ 50,000-\$ 75,000$ income category.

In all areas between 57 and $62 \%$ of white households owned PCs while between 34 to $50 \%$ of black households owned them ${ }^{24}$. In 2004 it was estimated that $67 \%$ of the white population had internet access and only $43 \%$ of the black population had access ${ }^{25}$. Given the difference in population sizes this means that in the USA white and black people may have entirely different experiences of online life - it is much more probable that black people will encounter white people than vice versa, and it is highly probably that most contact will reflect offline interests and segregations and maintain those segregations online.

\section{Cybermind}

Cybermind is an Internet Mailing List which was established to discuss the "philosophical and psychological implications of subjectivity in cyberspace", but actually discusses many other topics including List member's personal lives and experiences. It was founded in mid 1994 by Alan Sondheim and Michael Current. Michael died shortly after the group's founding and for many years Alan was the sole moderator for the List. In the period under consideration the List had three moderators, Adam, Dave and Paul ${ }^{26}$. There have previously been female moderators of the List and it is not a position reserved for males.

\footnotetext{
${ }^{23}$ K.D. McKinney ““II Feel 'Whiteness' When I Hear People Blaming Whites:” Whiteness as Cultural Victimization", Race and Society 6, 2003: 39-55.

${ }^{24}$ Jayajit Chakraborty, M. Martin Bosman "Race, income, and home PC ownership: a regional analysis of the digital divide", Race \& Society 5 2002: 163-177, p 168.

${ }^{25}$ Time Almanac 2006: 565.

${ }^{26}$ In this paper, List members have been given pseudonyms.
} 
Over my ten years of study it can be said that, in daily life, race and ethnic identity were rarely of concern on Cybermind. They are largely invisible in accordance with ideology and seem much less a focus of interest than gender, which was a common subject of discussion and protest. It thus becomes important to observe when these kinds of identity do become mobilised and do disrupt the smooth flowing of the List.

People will sometimes mention nationality, in order to stress when a piece of news, or a world event, has an effect on them as non-American. 'American' is the dominant and unstressed identity, so interest in non-American news may need explanation. NonAmericans do not always seem sure that Americans will follow these references. This is rarely disruptive. However in the period in question, mid 2002, it seemed clear to many on the List that the Bush Administration was going to declare war on Iraq no matter what, and nationality started to become important. Criticism of American policy was marked - especially from Australia and the UK - and it often seemed that criticism of the Bush Administration shaded into criticism of Americans generally - offline categories tended to blur. The numbers of accusations from Americans of the 'antiAmericanism' of non-Americans increased markedly, and some long standing relationships on the List became fraught or even terminated. There is no evidence from Cybermind to support the proposition that nationality has, or will, become less important in terms of self-identity online. If anything it appears to increase when it becomes marked as a matter of difference, as will be shown to be the case with race.

As J. Lennie et al have remarked, a sense of community in the West is frequently maintained by steering clear of contentious topics (in her case the discussion of Aboriginal Land rights by white rural and urban women in Australia). Harmony appears to depend on suppressing the claims of some (by their voluntary silence) in order to prevent others from leaving ${ }^{27}$.

However, at this stage silence did not seem an option to many on Cybermind and there was considerable angst. Eventually the List would approach breakdown, and people would leave, either because of the politics or because of a shift into what some saw as triviality which came to swamp the politics (perhaps in an attempt to restore

\footnotetext{
${ }^{27}$ J. Lennie, M. Grace, L. Daws \& L. Simpson, L "Empowering Online Conversations: A Pioneering Australian Project to Link Rural and Urban Women" in W.Harcourt ed Women@Internet: creating new cultures in cyberspace, Zen Books, London 1999: 193-4.
} 
commonality through one line jokes and sexual innuendo $)^{28}$. The race issue may have been more open to being marked in these circumstances as it gave some brief break from the fraught internal dissensions of the List. There were newcomers present, who were both critical of the List, and phrased their critiques in terms of race. These people could easily be categorised as outsiders by List members, and could be used by some to make indirect political points, and to give a semblance of internal unity. Nationality and race were already emphasised by the background nationalistic disputes. Nevertheless, the resultant debates came out of an interactive process, rather than out of deliberate action by established List members.

There are multiple interpretations of events; this is the nature of culture. What is given here is but one interpretation, and other List members could give equally detailed, but different versions of what happened. It is to be hoped that people who participated will take the opportunity to describe their version of events in the comments section of the journal and thus make some of these versions plainer and add to the richness of description and analysis.

\section{Ethnic and National Distribution of List Members}

It is not possible to give an ethnic distribution of List Members, but it would be safe to say that most active members are 'European white', if not all with English as their first language. There are no visible groupings of people by ethnicity on the List (although sometimes people group by nationality), but it is possible to give some idea of the breakdown of subscribers by country. The List was overwhelmingly US oriented (c.166 members), with Australia coming second (15). The proportion of the Australians who actually posted was much higher than for people of US origin. Other European countries make the next largest category. There is a marked absence of people from Africa, which would be expected given the relatively low levels of Internet use there at that time. A general absence of people from East Asia is perhaps more surprising, but probably reflects the Western cultural background of the List.

\footnotetext{
${ }^{28}$ See Marshall (2007: 204-08).
} 


\section{Background discussion}

I have elsewhere described List sensitivity around issues of anti-semitism ${ }^{29}$ and shall here briefly describe a discussion of racism occurring about a year before the main series of events, to give some notion of the background 'ideas' of the List. The most common argument was that humans tended to be naturally afraid of difference, but with a degree of awareness, listening, and 'intellectual' effort this could be diminished. Thus Heloise wrote:

If $[[\ldots]]$ someone calls me a racist I think it is best to examine the reason for the other people calling me so. They might be right, I am white, living in a predominatedly white society ${ }^{30}$

Lisa, after claiming she had adopted multi-racial children, stated that she "recognises that there is something in me which approaches racism". Mark after arguing that racism arises from the hunter-gatherer stage of human development claimed that racism arises “when our 'intellect' fails to override our natural tendencies". A self proclaimed multiracial member wrote racism is "a sign of your intolerance of the human condition". Aeshya, from the Middle East, suggested that we are not born racist but become racist, and gave as evidence the ways that her children picked up local prejudices. She also suggested that racism was strongest amongst the poor and marginalised. Lucian remarked that as he is multi-racial he is "sensitized to the racist undercurrent in many people's speech", and suggested that if you think you are pure and not racist you should ask minority members what they think, and "stand way back". In general the comments are as one might expect from a humanistic group with leftist leanings; they see racism as a problem, that it is possible to be unaware of one's racism, and that 'minority' members are the experts on racism. At the least these statements indicate a potential for dealing with racial difference in a relatively non-combative and sensitive manner.

\section{The Main Events}

The events described occurred in 2002 between Thursday $15^{\text {th }}$ to Tuesday $20^{\text {th }}$ August, and Sunday $15^{\text {th }}$ to Friday $20^{\text {th }}$ September. During the first incident there were over 200 posts, and during the second there were over 500 posts. This paper concentrates on the first incident. It perhaps needs to be said that while large numbers of posts tend to mark

\footnotetext{
${ }^{29}$ Marshall (2007: Chapter 9).

${ }^{30}$ Spelling and grammar have not been corrected. Ellipses I have made in the text are indicated by $[[\ldots]]$. Other ellipses are punctuation marks within the text.
} 
arguments on this list and emphasise its soap opera intensity, there is no particular link between intense posting and discussions about race

The events open with gender. A man forwarded an article claiming that men are using the Internet to exploit women romantically through netsex and that women should not be so 'available' online - effectively blaming women for the exploitation the article was protesting against. In response, Claire from Belgium posted the following tale:

2 years ago I knew a girl here in Belgium, she started on Internet in July 2000 , discovered chatting almost immediately ... she was really into funk music ... chatted mostly with Americans, met a cool black guy, fell in love, had cybersex, the works. Went to New York 2 months later to meet him, was very much in love, came back, found an E-mail from him, telling her: "Hey, it wasn't just me, it was me and 4 pals leading you on! We pulled straws on who got to fuck you when you came over!!!"

Ah well, she was too gullible, but on the other hand Internet isn't as "evolved" in Belgium as it seems to be in other countries, so down here we couldn't even imagine that anyone would even think of doing stuff like that.

There was a brief discussion about gullibility and women. The post seems to have been framed by List members, who commented, in terms of gendered behaviour around sex. Eventually Howard responded with his first post to the List in which he read the post entirely in racial terms:

Haha! That's a very funny STORY. Of course, I'm pretty sure that's all it is, a story, because the whole construction of it reads as a typical thinly-veiled racist fantasy. I've been on the net long enough to recognize bullshit, and you just dumped a steaming pile on the List.

You folks are pitiful. I thought CYBERMIND was supposed to contain at least a slightly higher level of discourse than alt.return.of.the.third.reich, but I guess I was wrong.

The story is here perceived as a racist 'urban myth' with no basis in truth. The presentation of the story, and presumably the few comments on it, seems to Howard to indicate the racist orientation of most of Cybermind. He seems to categorise the whole List as potentially neo-Nazi, although this could be an attempt at humour through exaggeration. His remarks also characterise him as a List outsider, whether with right, or expertise, on his side or not. There was not that much time for other List members to respond to the story but given the story was presented by an established member as true, it would be accepted as true. No one had previously mentioned race in their remarks on the story. If they had done so in a hostile sense then this could have been seen as a 
racism which would put the professor on the outside of the official anti-racist posture of the List - especially if racism is to be 'solved' by ignoring race.

Initial responses to Howard from List members agreed the story sounded like an Internet legend, but urged that it be seen in a wider context of List messages and in terms of a frequent motive of romantic disillusionment and gendered behaviour. Responses were quite good humoured. For example, Ronald, who was normally amongst the most combative members of the List, wrote:

I agree though, this reminds me of the $\$ 500$ cookie receipe story. by the way, thanks for the heads up on alt.return.of. etc.

a great cite :)

Some people seemed mildly offended by Howard's remark that the List was 'pitiful' suggesting that 'pathetic' was a better term. Wendy said that Howard was being "way too defensive" and gave an example of a similar story, to which Howard replied:

1. Do you notice how the framing of the above story is completely different from the original story I complained about? Earth to Cybermind. Is anyone home?

2. Did you notice the coding in the original story? Read it again. Now let's List them.

First, the Setup:

1. You knew a "girl" in Belgium. Hum, no race indicated.

Well, it was Belgium, not Germany or Portugal, so most likely she's "white."

Transgressions of White Supremacy:

1. She was really into "funk" (Black) music. Isn't everybody? Oh, I see, that was to point out the unusual nature of that interest for a "Belgian" girl.

2. She met this "cool" Black guy. Hum, why was his being Black relevant? You didn't say, I knew a "white" girl in Belgium., but for some reason, the race of the guy was important to the story.

3. She talked mostly to "Americans." I guess she wasn't as enamored of her fellow descendents of King Leopold as she should have been. Another transgression.

Punishment for Transgressing the "Rules":

1. She got fucked, dismissed, and her heart broken. 
Implicit Lesson of the "Story":

1. Stay away from those Negroes, especially the cyber ones.

They might seem nice, but then they turn into O.J. Simpson.

It seems also that Howard takes the location of the story in Belgium, not as indicating its authenticity and closeness to Claire, whose Belgian nationality he was unaware of, but as an indicator that it 'happened to a friend of a friend'. At this moment Dave, as moderator, intervened by placing Howard within a context of 'race sensitivity'.

Aren't you seeing your own agenda in this? You seem to be well known in Google for looking for racist issues and bringing them out in online forums.

Personally I know a lot of white guys that would try this same thing when I was growing up $[[\ldots]]$

Since you've only been on the List since monday, let me challenge you to go into the archives and find more racial stories that we've been telling amongst ourselves. I think if you look around, you'll find that we're a pretty diverse bunch and you're finding prejudice wherever you look, even where it isn't.

Howard's reply is being categorised as personal bias unrelated to reality. As implied, in the English speaking world it is relatively common to argue as if awareness of racism was a form of racism. At the same time, Dave coded Howard as an outsider unfamiliar with the List. Dave's move is also empirical. He challenges Howard to find further examples of racism, particularly explicit racism, obviously confident they cannot be found in any number - something I would have expected also - and thus challenges Howard's presentation of his expertise. This is a challenge Howard does not take up, and it would not be easy to take up because of difficulties of searching the archives and rarity of discussion. As already stated race is not a recurrent theme on the List, and explicit racism would not meet with approval. The List Manifesto states that offensive language will not be censored but "racial or other bias slurs will not be tolerated" which remarks were added to the manifesto after a struggle in the first months of the List's existence over issues of racism and free speech.

Dave's comments also recode the original message in terms of gender - this is how men (or 'lots of men') behave. Whereas Howard's initial strategy had the effect of blanking out the gender exploitation expressed in the original email through reference to race (and indirectly of silencing Claire who contributed nothing further to discussion), Dave is using categories of gender behaviour to overwhelm categories of racial behaviour. In 
Dave's argument the supposed universalism of gender effectively removes ideas of racism.

In this initial exchange we can see the setting for the struggle over categories which guide the rhetoric of the debate, and which we might characterise in terms of the following distinctions, which tend to become polarities:

\begin{tabular}{|c|c|}
\hline Established & Outsider \\
\hline Knowledgeable & Biased \\
\hline Gender & Race $^{31}$ \\
\hline
\end{tabular}

Howard will be unable to overcome the Established/Outsider categorisation and will try to establish himself as Knowledgeable.

Another new List member (Ronda), who was studying online dating for a $\mathrm{PhD}$ thesis, manages to completely strip the race issue away from Howard's comments:

The response by Howard is beautiful and I totally agree with his reflections and responses to a rather narrow minded opinion of what one may experience from Internet/Cyber Dating [[...]]

There is great potential for this mode of communication to open the world to those who would otherwise never be exposed to such vast and diverse opportunity

Dave takes up the absence of race, and the presence of knowledgeability, from the above and responds:

Welcome from lurking. I agree with all your statements and notice that you use no racial bias in those findings. Since you've been here a while longer (since May it appears), do you find a hidden racial agenda as Howard does below on this List?

Dave is using the data available to him as moderator, to see how long people have been on the List, and thus giving the impression of his wider expertise. Here he appears to be trying to recruit support from someone who might be considered neutral, yet is more

\footnotetext{
${ }^{31}$ Gender and race are, of course, not polarities and are not mutually exclusive, but they do refer to things which can become polarised. Thus gender is polarised into male and female, and race into 'black' and 'white' (in this case). Gender and race in this sequence of events, also tend to be categories which overwhelm each other. Thus, as will be seen, when gender is deployed it aims at negating race as difference, and when race is deployed it aims at negating gender as difference.
} 
established, in favour of the List. This emphasises Howard's status as outsider, uninformed, and without connections.

Wendy intensifies her earlier response, accusing Howard of bigotry and being engaged in "racial bitching" - also using awareness of race as an indicator of racism. Her story was intended to show that similar things happen irrespective of race. She concludes, “we're all very much at home here, where are you?", which again emphasises Howard's externality to the group and his lack of expertise about it.

Responding to Ronda, Wendy ties her to Howard ("i think Howard, and you, need to sudy the subject matter before going off like this"), showing that what can seem like neutrality to one, can seem like joining together to another. The ambiguities and uncertain references of Ronda's mail seem hard to resolve. Wendy continues:

in reality, a person was used and Howard would rather focus on his own personal agenda, instead of fairly focusing on the actual problem area.

By which it is implied that Howard is more interested in race than in gender issues perhaps indicating not only bias but also moral blindness. Whatever his expertise, he is portrayed as not knowledgeable about some things. She continues:

why does Howard have such a problem with race? why is he so hostile to a group that he has not taken the time to know and understand? it seems somewhat pathetic that he needs to jump into a discussion with flamboyant, and unreasonable comments to get attention. just like a bad little boy who says dirty words in front of mommies friends for the effect.

With these remarks, Wendy also categorises Howard as immature, or not able to join adult conversations, and thus as outsider again - Cybermind's membership is very largely post-teen. This is not a move taken up by others. The ante then heightens as Lucian appears to take offence, writing a series of mails which would be hard not to see as patronising, while trying to establish himself as a 'non-white' with no problems about race as such (which is quite contrary to the implication of those of his mails quoted in the 'background discussions' section of this paper, but that was against a different opponent):

Somebody get his feelings hurt?

Lucian

Living large in the most racially mixed place on Earth.

and 
Take off your racial hair shirt.

If more 'negroes' stopped reading race into everything, they'd be much happier.

Lucian

Mixed and maladjusted in Hawaii

and

Howard should come over to the II [[Interracial Individuals]] List at Harvard where he could get shouted down by a bunch of tragic mulattos.

He should also check out Interracial Voice web page.

[[http://interracialvoice.com/]]

That'll give him something to bitch about for the rest of his life.

This message is self referential. Lucian has been a prominent member of the II List and thus counts himself as one of these 'tragic mulattos', but I doubt if anyone on Cybermind is aware of this. Certainly Howard would be unlikely to be. It is hard online to keep in mind how little different groups interact, and thus how little people may know about each other. In the 'background discussions' section above, it was Lucian who initiated the racism discussion by criticising a now vanished member for wanting shop workers to speak to him in English, and claiming his own sensitivity to such matters. So whereas Lucian may be attempting to state not only his qualifications to speak as 'non-white', referencing a whole 'politics of the end of race' and trying to be self deprecating at the same time, these factors will almost certainly not be seen. However, there is a clear response to the perceived patronisation, from another new black List member - MD - who now makes his first post. Race serves to draw out people, when they feel marked.

It beats being shouted down by a bunch of tragic white supremacist.

I have been watching this thread, and find the patrtonizing attitude insulting and offensive.

Watch TV everyday and I get an all white assault that is disgusting..

MD's use of the term "tragic white supremacist" almost certainly refers to Lucian's use of "tragic mulattos" and is probably intended as a contrast referring to society in general, not specifically to the Cybermind. However, because of non-resolved ambiguity (at this moment) it can easily be seen as another accusation that the List is racist. Lucian's response to this post is also easily seen as dismissive:

Jezzus, where do they come from? How do you know who's white who's not? You should be out on the mall whining about reparations. 
This again brings up the motive of race being invisible on the Internet in order to dismiss claims about race, while similarly referring to an offline politics with fixed positions taken for granted. Dave then points out that MD has only been on the List a few days, and asks what brought him to "our little community" - identifying him as outsider to the group - and points out that nobody with experience has agreed with the implication that the List is racist. This bypasses any issue about the way it is possible to perceive Lucian's responses, and Dave must have seen some of these messages, but Lucian is a long standing List member and normally would not seem to have a 'racial agenda' as clearly as the newcomers might appear to do, as they have made no posts on other subjects. As established, Lucian's behaviour can be given the benefit of the doubt, or not perceived at all. MD replies to Dave indicating that he was responding specifically to Lucian and not to the List as a whole.

How did you interpret my comments as implying that the List community supported this guys posts?

I posted my thoughts on what this guy posted..end of story

However categories when activated are hard not to generalise. MD then responded in a general manner to Lucian's bringing up of reparations for slavery, by writing that the "whinning will shorrtly become a roar". Dave appeared to see this statement, which is fairly ambiguous again and probably referring to offlist action, in terms of a threat to flood the List with off-topic political posts - this could be worrying because the quantity of political posts about the Bush Administration's 'War on Terror' and other matters was already threatening List cohesion. However irrespective of Dave's intention, this could be seen as a move to silence 'black issues'. Dave writes:

Don't threaten the long established List with an unwanted agenda.

There's no need for it here. This thread is going nowhere, move on.

MD reacts harshly to the "Move on" - possibly to him it sounds like a policing instruction not to 'loiter' around - and asks Dave what he is doing on the List. Dave gives a short biography and then proposes his vision of the List, emphasising its cultural variety and the difficulties of recognising gender "let alone race or culture", reinforcing standard claims that these are irrelevant online. He also points out that Claire has a "lot of background" which clears her from any accusation of racism (she is established and known), and restates Howard's outsider position:

We have regular contributors from most continents and lots of insight into work affairs outside each of our nation's veiwpoints. We have had discussions one most things and there's a sense of support amount us, many having been here as long or longer than I. Many of us are diverse and we've 
had many discussions about what our view is of each other, many of us not even properly guessed on gender, let along race or culture. Claire has a lot of background which makes Howard's comments unwarranted, but then, he hasn't been here long enough recognize that either.

In the same letter he shows that the comment "move on" was intended as an invitation to start another topic - perhaps silencing one thing to avoid flame war, but suggesting another opening - something which he continues in a response to Ronda:

I think Howard read too much into Claire's story and it pushed a personal hot button. That happens around here at times, then we move on to other topics...

Why don't you start a new subthread (with a new subject since many are already deleting this thread unread) talking about your dissertation

Again Dave indicates the superior knowledge arising from his position - the only way he could know that many people were not reading the thread was if people had been writing to him about it - which would probably not be that many. It further implies his established centrality to the offlist communication network - the invisible community of the List. Whether his statement is true or not, it shows the moderator's power to create the appearance of majority - especially to an outsider ${ }^{32}$. His stating of List history as normative reinforces this. Dave adds "We're all subscribed equal, until we delurk and post!", implying the only inequalities online depend on ability to compose text or intelligence. The internet is thus claimed to be a great leveller of offline inequalities, with the implication these inequalities are not relevant and thus out of discussion.

Meanwhile, Ronda had written:

I was so enjoying the discussion on Internet dating.... How the hell did we all end up on this path?

Oh, what the hell! I'm a tall, thin, attractive, educated, mouthy and well endowed, blonde, white woman from the Midwest, USA...

Gimme your best judgmental opinion on what my prejudices are....

Maybe I'm an idiot but one would have to be looking for an argument to run straight to racism after reading Heloise or [unidentifiable name]s responses....

This mail continues her deletion of the race aspect from Howard's responses, as if she had not seen it (other than by identification of her own race which would normally be

\footnotetext{
32 Later on Dave will imply that other 'black' members of the List have likewise taken offence at Howard's tone. Again he does not state who these people might be, what the category really refers to, or whether they are different from the people who have already commented such as Lucian. Nevertheless the claims still function as a mode of exclusion.
} 
unusual in this List), and introduces a gender/sex aspect, perhaps as a form of unification. Several members follow her request to go back to the issue of online dating, and restart the original topic, without the racial layering.

At this moment Alan writes to the List asking for a degree of calm. It is notable that as well as specifying his own anti-racist credentials, he praises Howard shifting Howard into the category of expert (he has previously published work by Howard), and proposes that anti-racists need to be more active. The whole mail is delicate and semi-apologetic.

Please, everyone, try and keep cool in the heat this summer.

I've been running the List, co-moderating, for eight years now, and haven't seen any real signs of racism here. I may be naive, but I'm sensitive to it.

Actually, I have - and the people in question were unsubbed and blocked; they were trying to raise hell, and did. (As far as I know, they were white, by the way, whatever that's worth. There was also an anti-semite talking about "the Hebrews.")

I've admired Howard for years; he runs an excellent newsletter that I used to read, and his activities are well-known. And given the racism in the US, which is all I can speak of coherently (well, a little bit Japan), more activism is necessary.

I do worry about throwing race/racial/racism around on this List - at each other; it doesn't help anyone at all.

Forgive me if I'm out of line here -

Jennifer agrees with Adam - saying she was about to ask people to cool it as well. She says she enjoys discussions of race and gender "but only so long as the discussions remain civil". MD has a somewhat different attitude, claiming a special basis for his comments based on his experience and hence claiming expertise. It will later seem that for MD only black men are the victims and fighters against racism.

I've been living black all my life and I doubt that you recognize racism as I do or that you have the same sensibility to it.

I don't throw race around, it's ever present and someone insinuating that we have to look for it oviously isn't as sensitive to the issue as they could or at a level that would effect some change in this country $[[\ldots]]$

I know personal rights have been greatly deminished at this point in time, but to my knowledge, freedom of expression hasn't been totally eradicated as of yet. 
This moves into discussions about the Bush Administration, 'dumbing down', and the power (or lack of it) of intellectuals. It offers some hope of finding common ground, and a common category, and shows that List member's representation of Cybermind as friendly is not without some basis. However, this common ground is also potentially dangerous in terms of the existing splits over the Bush Administration. The truce is also not stable, in an asynchronous environment, because some List members still have to read and respond to earlier mails, and will do so before reading the later more peaceful mails. Thus, Lucian reintroduces reparations and his multi-raced background, wondering:

Should I take money out with my left hand and give it over to my right hand so that some of my ancestors can pay for oppressing others of my ancestors ;-)

This might ignore the issues of whether all 'multi-raced' people have the same access to the mainstream as others, and of whether there is more than one way to give 'reparations' - but this dose not seem to be rare in American discussions of this subject.

Howard continues his discussion with Dave:

I wasn't saying that guys aren't assholes or that Black guys can't be assholes. I'm Black, and I know a lot of Black male assholes. That wasn't the point of the discussion.

Gender behaviour is taken for granted. It is assumed to be common, something we can all agree upon. He continues:

I was simply trying to point out that whether intentional or not (and this is key, White Supremacy is not about the KKK or Neo-Nazis, it's about institutional racism and privilege), the framing of the story was done in such a manner as to undergird White Supremacy. It's not about the person who told the story as an individual, this is a structural problem with people's worldview and assumptions.

That's one of the reasons I chastise Cybermind as a whole, and not just the individual who told the story. This is not a single individual's problem, it's all of ours.

It seems that he is attempting to include himself within the criticism, and not push himself outside the group - but the race theme and his 'racial categorisation' will not make this easy. Nor is it perhaps likely that a largely American audience will respond positively to an implication that morality is group based and not individual. He continues his theme of racism not being an individual issue in another mail: 
I don't believe that anyone here has a necessarily conscious racial agenda. The people here may even mean well and refer to themselves as liberals.

Unfortunately, that's besides the point. The reality of White Supremacy and Racism is that whether intended or not, it leads to inequitable distribution of wealth, power, and life chances for the MAJORITY in the U.S. and globally.

In other words, good intentions are not enough.

Given this, it is then difficult to figure out what Howard might have expected in response to his first email. His argument may well be correct, but there is little place for movement or interaction. Even if 'everyone' agrees, it does not solve the issue. Howard also responds to Lucian's, 'multi-racial' take on the issues:

Are you sitting down? OK, here goes:

All Black people are mixed and interracial.

One more time, because I know you're slow:

ALL "Black" people are MIXED and INTERRACIAL.

Blackness is not and has never been specifically about genetics, phenotype, or skin color.

Sorry dog, but there are no Louis Farrakhans in this room.

He will also respond to Lucian's "where do they come from" remark, by giving his location in the US, and asking if anyone wanted to meet for coffee, and in response to the message from Ronda about guessing her prejudices writes: "Who cares. What I want to know is, are you single? ;-)". In this he joins the movement to diminish the breakdown by implying the uniformity of male/female interaction.

Another member, Peter, who was possibly the most marked left winger on the List tried to introduce a broader leftwing perspective with something of an apology and a remark about unaccustomed aggression, this referring to a List which has had, and will have, many fierce arguments.

Sorry Howard,

I seem to have missed most of this strand - perhaps because of the subject line - and so I have little idea what kicked the row off.

But it seems way out of the norm in pungency as I join in.... 
Much as white supremism (?) (not -acy??) and racism are loathsome, the inequitable distribution of wealth etc ... in US and particularly globally is surely about less than $1 \%$ of the population (perhaps 2 to $5 \%$ where there are concentrations of powerfools) "running things" and up to $99 \%$ of the population "being run".

How much has this got to do with whiteness or blackness?...

But where the colour is (mostly) taken out of the situation the situation seems to remain the same.

The real enemies have in each case cleverly divided and still rule.

On Cybermind there are disagreements and misunderstandings but no enemies as far as I can see.

This also seems to render the issue of race secondary, or invisible, when compared to other actions/things, while restating the nature of Cybermind as a place with disagreements but not vicious ones - something Peter will soon learn is not the case when a member not that much later comes to the List pseudonymously and proceeds to attack him over his attitude to the Bush Administration. Chris's move towards generalising the problem is not taken up by anyone else.

Another poster introduces another kind of cliché, that of the black male as sexually potent. Helen, after announcing her return to the List after a busy summer writes:

if the belgian girl + black american guy e-love story gone bad had actually turned out good, would we be talking about racism?

\{the way i read "black guy" = sex god, i mean, you know, black guys (well, the few i've had the pleasure to "know") are objects of pure lust...!!! so, the belgian girl may have been "deceived" but the sex was probably really $\operatorname{good}\}$.

Oddly, neither MD nor Howard visibly object to this racial characterisation. Heloise responds: "Please don't suggest that all black men are good for is sex ;-)". Helen replies by referring to the sexual one-liners that she and some other members exchange with each other on the List:

;- ) (i'm just glad this conversation isn't going to mention breasts...) of course Heloise, $i$ do mean that in order for the sex to be good, the minds have met in a powerful way first....!!!

a good discussion, nay, argument (!) (and let's leave spanking out of this one) is a great aphrodisiac... which brings us back to cyber romance...

Heloise responds to the one-liner hint... 
I feel quite restricted

no spanking, no breasts ;-)

And Helen continues:

restriction is also a good aphrodisiac

This is a move taken up by several other people and seems to be a relatively safe game which provokes no protest and may assert business as usual among the established List members. Race as fragmenter, is supplanted by ties of gender, joking and flirting. After a few more exchanges, any kind of serious discussion of the issues then wanders into a long set of exchanges about sex and food, bringing to mind Hage's remarks about white-liberals showing their multi-culturalist credentials by displaying their eating habits $^{33}$. Other List members imply they are using the delete key or are reading other threads and thus giving themselves the last dismissive word. However, a few people imply they agree with Howard. A female ex-moderator who has been absent from discussion until now, takes a position similar to those taken in the 'background discussions' of a year earlier:

What I think Howard is getting at is that white supremacy, like patriarchalism, is expressed through assumptions about how the world works that are taken for granted [[...]] someone comes along and recognizes and challenges the underlying racism behind those assumptions, and then the teller, and/or others, begins to rationalize the way the story was told in such a way that its racist assumptions are explained as not being racist.

I tend to think that we are all, every human one of us, are racist in some form, and the obligation we have is to recognize it and defuse it in our own beings, not letting it guide our actions. I think that racism grows out of the territorialism of our animal condition.

This attempts to make race and gender similar and meeting points, but in a way this universalising of the problem, perhaps makes it one that we personally are not responsible for. Wendy replies:

$\mathrm{i}$ think racism grows out of fear. anything that causes fear should bedominated or controlled... i much prefer the "get to know your neighbors and learn to be friends working together and combining strengths" type of culture.

The debate then ends in silence, and the issue is not pressed. However race bursts into prominence again several weeks later when it is again contrasted to gender.

\footnotetext{
${ }^{33}$ Hage, Ghassan (1997) "At Home in the Entrails of the West", in Helen Grace et al. (eds) Home/World: space, community and marginality in Sydney's West, Sydney, Pluto Press 1997: 118-24, 130-4.
} 
This next conflict begins with Ronald talking about the Christian dark ages, and comparing them to the Taliban. "The muslem's dark ages will expire" he writes, while the US might fade also under the current leadership. Other people join in criticising the Bush Administration for its fundamentalisms. Margaret, who is Australian, makes a number of remarks about America, for which she later apologises. She goes on to write that President Bush is:

prepared to sacrifice almost everything that makes the US so admirable.

In years gone by, there was much to be admired about America. I remember as a child watching television shows and movies that showed the unity of family life, moral principles and motivation.

MD responds:

You're reporting how there was much to be admired "back then", except that as a period of terrorism for black people and it always gets ignored when people are reminiscing about the good ole days. People were ecluded from eating places, water fountains, schools, restrooms and opportunity[...]

The good ole days, for who?

Jennifer writes, generalising the racism:

Thanks for reminding everyone of that. I'd also like to add that things are still pretty terrible for Native Americans, especially out west. I pitched a fit over a "No Indians" sign about ... hmm, a little over fifteen years ago...

$>$ The good ole days, for who?

Why, for the good ole boys, of course.

MD will not have this:

And girls, for after all when the truth is told, you went to the same schools,shared the same wealth and experienced the same priviledge as the good ole boys. When we were marching for rights the most violent and out of control people were white women..

Lisa thanks MD for reminding her of this, Aeshya asks MD to elaborate a little. In the background the Australian Margaret states that she would never want to go to America again after her last experience, and Peter has posted a call to arms from the Third World which states "I, the man of colour, want only this: That the tool never possess the man. That the enslavement of man by man cease forever". To which Aeshya remarks "yes, and while we're at it, can we add "man's enslavement of woman"? Would be nice...". So the scene is set for gender, race and nationality to be mobilised again. 
MD remarks that race relations are at the worst ever, that multi-culturalism as subject for teaching has been destroyed, and that he has even worked with children who thought black people had tails. Perhaps reacting to the earlier way that unifications of gender had seemed to undermine the exploration of race, MD explains his feelings about white women:

We would march through a town or through the streets of Houston and white women on the sidelines were the most vociferous in their cursing, name calling, spiting, throwing things and generally demonstrating a lack of control. Often I would notice white men trying to restrain them, with great difficulty. It offends me when I hear about the complaints of white women when they have benefitted by the same priviledge as their white male counter parts. $[[\ldots]]$

When we tried to get schools, or neighborhoods integrated, we received the same resistance from white men and women. [[...]]

Nixon supported and promoted the women's movement as part of his policy of "benign neglect" toward black people. He knew the result of the movement would be that white women would take positions from black men, which is exactly what happened. Let's get real..

MD then argues that white women corrupt black women through feminism, lesbianism and witchcraft - in effect alienating nearly all the vocal women on the List. Aeshya will make a common point in asking:

why does one group's battles have to cancel out another's? I think we need to recognize that the fights against racism and sexism are inextricably bound. In fighting one, you fight the other. And this is a view that many African American women share and propose. To state the obvious, more than anyone else, they have had to bear the brunt of both racism and sexism. Their struggle has been nothing short of heroic.

However MD appears to see Black women themselves as an obstacle, and as unheroic, as much as they accept feminism. He further argues that contraception and AIDS are genocidal plots against black men. Neither position is found convincing by other List members.

Several people, who had in other debates not been happy with their gender being obliterated by statements to the effect that gender was invisible online, responded to MD by stating that he did not, and could not, know their race online, and making this supposed ignoring of categories a call for universal experience. For example: 
How do you know I am white? indeed I may not even be female. why not just be available to share ideas form "people" instead of "types".

After all we all share a common humanity. Isn't that what counts?

Likewise the difficulties MD had with Lucian can be completely unseen when compared to the largely engaged way with which some members of the List have interacted with him. Thus Adam writes, agreeing that whites are racist:

But you don't seem to understand how you yourself come across; you have repeatedly attacked people personally, calling them names, etc. etc. No one is doing that with you in return $[[\ldots]]$

Look at it this way - within one or two posts of mine, you were already comparing me and Aeshya to George Wallace. How do you think that comes across?

The point is made again that MD does not know the people he is criticising and is thus an outsider. To which MD responded, apparently able to see ambiguities in communication one way, but perhaps not the other:

That was your interpretation of my interpretation of some thing that you said. $[[\ldots]]$

I have been called names, right from the start. I reserve the right to respond. If you don't want me calling names, then don't call me any.

This conflict also allowed people to make some kind of peace with Howard, who by comparison was perceived as rational and insider - especially to the extent he disagreed with MD. MD was classified as trying to inflame the List, or as a 'troll' in Internet vernacular, especially after the posts about genocidal conspiracy.

MD was eventually thrown off the List by the third moderator, Paul, who had taken almost no role in the previous events, in response to his perception that MD was abusing Lucian, after Lucian alleges that MD:

sent me an anti-Semitic screed about the Rothchilds which he doesn't seem to have the courage to post to the List.

The question of trust is raised here, but Lucian is established and knows that allegations of anti-semiticism are not likely to go down well with Alan, and will further mark MD as an outsider and as biased. 
Mark, who was the source of most of pro-Bush argument on the List, wondered why it took the List so long to see that MD 'was' racist and misogynist, and proposed that it was because everyone else was so politically correct:

What I found amusing was how people DIDN'T call it racism because the perpetrator was black. Everyone knows it's politically incorrect to call a black man (or woman) racist! I was making bets with myself as to how long it would take.

In the long term, despite these disruptions the List could go back to normal when the disputes were largely confined to outsiders one of whom was removed. MD was unable to build alliances, he was defined as outsider, as biased, and as unable to deal with gender. No one objected to his removal. Howard left quietly some time later, apparently out of boredom with the List's off-topic discussions as he returned at one time asking if Cybermind ever stayed on topic and engaged in more than "chit chat". However, when other disputes occur between established members, and are classified in terms of nationality rather than race, the return to normality and the silence of dissent will not be as easy, and the List changes, perhaps forever ${ }^{34}$.

\section{Discussion}

In these debates, arguments about race, and dividing people by racial categories, served to come between people and made it impossible to talk about the racial issues which clearly affected some members, and which formed a deep part of their experience. People who would normally dismiss the argument that you don't know what a person 'is' online used it easily when it came to race, and protecting themselves. In other contexts gender could and did function in a similar dividing manner, except that Cybermind has many established female members who could support each other and this mutuality allowed those debates to progress more smoothly. However, in this context, gender was mobilised to show the supposed universal similarities between groups which were separated by race, and to promote unity. The rhetoric assumed that even the divisions of race could not stop sex and attempts at cross-gendered intimacy. Gender overwhelmed race, although $\mathrm{MD}$, in particular, saw race as overwhelming gender, which was very much an outsider position. Therefore it would seem that gender categories are not always makers of separation and markers of difference, even in politics, which probably stems from Western gender's association with heterosexuality

\footnotetext{
${ }^{34}$ See Ghaly's paper in this journal and Marshall (2007: 204ff and passim).
} 
and intimacy; positions which might be challenged onlist, but were assumed in practice by the heterosexual members.

We can also see how the rhetorical importation and assignment of offline categories is one of the prime tools of cultural persuasion and of cultural construction. As implied by Hopkins and Reicher, the effective rhetorics deployed in these incidents involved a) people defining category boundaries of established and outsider, or expert or biased; $b$ ) trying to make the rest of the List and the 'speaker' part of a common category, especially in contrast to the opposed category; c) constructing the recommended actions or beliefs as congruent, or prototypic, with this self and group category: d) making opposing arguments and arguers represent an already known outgroup category, or be seen as biased ${ }^{35}$. In these arguments gender and race categories functioned to join and divide respectively, while in other situations gender could separate, and if one thinks of nationality as related to race/ethnicity, then it too could function to join Americans of different politics against non-Americans even of similar politics. In a way the 'soap opera' aspect of life online, with its heightened emotions, and tendencies to read others in ways they had not intended, its reawakening of disputes after they might have died down for others, contributed to this separation, just as it also might have made cross gender sexuality more available as the strategy for unification.

Events like these show that being online by itself does not allow people to discuss all the issues which affect them. People who claim outsider and critical positions, especially when they are not established in the group, will tend to be ignored, because they have not established their credentials or relationships with others, and the only way they can establish expertise is by staying silent on the issues which mark them as outsider and critical. Irrespective of these events, members of Cybermind, would still classify themselves as largely non-racist and non-sexist, and they would normally be right - condemnatory racial or gender categories are rarely deployed, nor racial exclusion practiced. Yet those categories can appear when people are challenged and put into opposition.

I have argued elsewhere that Cybermind at this stage of its existence was a group that existed to further the survival of its members and help them to make contacts in the

\footnotetext{
${ }^{35}$ Hopkins and Reicher (1997: 265-66).
} 
world. At that moment it was coming apart because of political disputes which involved, or evoked, nationality and offline politics. People recognised that the List was fragile and limited and, perhaps, that the first responsibility of members (however ambiguous they might be in terms of 'loyalty'), was to keep the List going - if possible without sacrificing their principles. Nevertheless people were departing, and departing obviously. In the ongoing disputes, concessions were able to be made for established members who had helped build up the list and have made contacts, but not for newcomers who could be perceived as adding to List disputes and who had not built up similar contacts, or the status which allows frequent postings without others complaining.

It is tempting to wonder what might have happened if Howard had not arrived at almost exactly the same time as the post which offended him. Would there have been more time for him to establish himself as an established group member, able to survive 'outsider' categorisation, in the same way that Mark had been able to do for so long? If Lucian had been absent (which was not uncommon), or more careful, would that have made a difference to List history at that point? What if people had made more effort to lower the ambiguity of their posts (assuming this was feasible)? It may well have been possible for established members to agree with Howard under other circumstances, and we can see this potential happening in the events above, but not being continued. The temporary shape of culture as well as depending on successful rhetorical moves, depends upon the history of categories, accidents and outside debates - it is subject to multiple causes and influences, and is a product of a sequence of many complex events.

In this case the pre-existing, but flexible, categories of Belonging, Gender, and Race seemed most important, although offlist politics impacted. Perceived expertise was largely allocated by membership of these kinds of categories, and argument flowed around the question of what kind of category an issue should be framed within - in particular whether the discussion was about race or gender. Part of the struggle concerned whether being black gave special knowledge of, or bias about, racism and whether being established or outsider gave special knowledge of Cybermind. These categorisations seemed to have more effect than the arguments themselves as the interpretation of moves is altered through the way the person making them could be classified by others. 
Even so, not all moves had the same effect. Some were ignored and had no effect in mobilising anyone. Those with effect gained from being repeated by others, especially those who were already established, even if the numbers who actually participated in this example of cultural formation were relatively small (less than $10 \%$ of the total membership participated).

It also seems that 'Black' and 'Black American' in particular seems to act as a prototype of the racial 'other' in a predominantly white American group, making it much easier to activate issues of race when people identified as such are commenting upon their experience. Gender seemed in this case to function as a kind of universaliser, something which could be used to cut across, or exaggerate, these differences. Race, or nationality, seemed to mark almost irreconcilable differences, while gender marked possibilities of intimacy and joining through heterosexuality. This latter might be unexpected as usually gender seems to part of the way ethnic groups often separate, males can usually marry out but females are expected to marry in. I have previously remarked that gender seems to act as a tool for, and marker of, intimacy in online groups ${ }^{36}$, but further work obviously needs to be done to find the limits to its overpowering of race, ethnic or national difference, and what external cultural conventions have on this. However in offline life in the US, people do associate across gender categories for mutual pleasure or intimacy and because of mutual dependencies and incompletions, but there is nothing which necessitates contact between polarised races. There is nothing online which would further this contact, and the drift apart into mutual suspicion and incomprehension can continue. It is not easy to overcome these offline divisions online.

Finally what is demonstrated is that even on a List where freedom of speech is supposedly pre-eminent and discussion open, people can be silenced, and it becomes difficult to ever have an argument which offends dominant members of the List, or the List in general, particularly if you are an outsider. MD was expelled, Howard was effectively self closed down and unable to become a permanent member, and Claire, whose posting inadvertently began it all, did not post on this or on any other issue during the rest of this discussion. The List, however well intentioned, was unable to overcome the racial segregation and stratification that existed in the wider society, when

\footnotetext{
${ }^{36}$ Jonathan Marshall "The Sexual Lives of Cyber-Savants", Australian Journal of Anthropology, Vol.14, No.2, 2003: 229-48.
} 
race became raised as an issue on the List itself, partly because of having to transfer a language and rhetoric from offlist in order to discuss the issues in the first place.

\section{Bibliography}

Back, Les (2002) "Aryans reading Adorno: cyber-culture and twenty-first century racism" in Ethnic and Racial Studies, 25(4): 628-51.

Baldwin, B. \& Flood, T. (1997) "Introduction: to Rhetorical Dimensions of Cyberspace", RhetNet.

$<$ http://wac.colostate.edu/rhetnet/rdc/edintro.html $>$

Biernat, M., Vescio, T.K. \& Green, M. L. (1996) "Selective Self-Stereotyping”, Journal of Personality and Social Psychology, 71(6): 1194-1209.

Bonilla-Silva, Eduardo (2003) Racism Without Racists: Color-Blind Racism and the Persistence of Racial Inequality in the United States, Rowman \& Littlefield, NY.

Bowen, MC \& Tal, Kali (nd) "interview with Kali tal: Re: boohabian texts" $<$ http://www.mdcbowen.org/p2/boo/kalis.htm>

Brown, M.K., Carnoy, M., Currie, E., Duster, T., Oppenheimer, D.B., Schultz, M.M. \& Wellman, D. (2003) White Washing Race: The Myth of a Color-Blind Society, University of California Press.

Chakraborty, Jayajit \& Bosman, M. Martin (2002) "Race, income, and home PC ownership: a regional analysis of the digital divide", Race \& Society 5: 163-177.

Elias, Norbert \& Scotson, John, (1994) The Established and the Outsiders (2 ${ }^{\text {nd }}$ Edition), Sage Publishers, Thousand Oaks.

Hage, Ghassan (1997) "At Home in the Entrails of the West", in Helen Grace et al. (eds) Home/World: space, community and marginality in Sydney's West, Sydney, Pluto Press.

Haslam, S.A., McGarty, C. \& Turner, J.C. (1996) "Salient Group Memberships and Persuasion: the Role of Social Identity in the Validation of Beliefs", in J.L. Nye \& A.M. Brower eds. What's Social about Social Cognition? Research on Socially Shared Cognition in Small Groups, Sage, Thousand Oaks.

Harris, David (1999) "Property values drop when Blacks move in because...: Racial and socioeconomic determinants of neighborhood desirability", American Sociological Review, 64(3): 461-479.

Holt, Thomas (2000) The Problem of Race in the 21st century, Harvard.

Hopkins, Nick \& Reicher, Steve (1997) "Social Movement Rhetoric and the Social Psychology of Collective Action: a case study of anti-abortion mobilization", in Human Relations, 50(3): 261-87.

Hopkins, Nick \& Moore, Christopher (2001) "Categorizing the Neighbors: Identity, Distance and Stereotyping", Social Psychology Quarterly, 64(3): 239-52.

Kahani-Hopkins, V. \& Hopkins, N. (2002) "Representing British Muslims: the strategic dimension to identity construction", Ethnic and Racial Studies, 25 (2): 288-309.

Krang, Jerry (2003) "Ruminations on cyber-race”, Dissent, 50(2): 58-63. 
Lennie, J. Grace, M., Daws, L. \& Simpson, L (1999) "Empowering Online Conversations: A Pioneering Australian Project to Link Rural and Urban Women" in W. Harcourt (ed.) Women@Internet: creating new cultures in cyberspace, Zen Books, London.

Marshall, Jonathan (2007) Categories, Communication and Control: A Study of the Internet Mailing List Cybermind, Peter Lang, NY.

(2003) "The Sexual Lives of Cyber-Savants", Australian Journal of Anthropology, 14(2): 229-48.

(2001) "Cyberspace or Cybertopos: The creation of online space", Social Analysis 45(1): 81-102

Mason, Eleanor Russel (1997) "Resisting Erase-ism", in Brillo No.3

$<$ http://www.brillomag.net/No3/erasism.htm>

K.D. McKinney (2003) “'I Feel 'Whiteness' When I Hear People Blaming Whites': Whiteness as Cultural Victimization", Race and Society 6: 39-55.

Miller, Daniel \& Slater, Don, (2000) The Internet: An Ethnographic Approach, Berg, Oxford.

Nakamura, Lisa (2002) Cybertypes: Race Ethnicity and Identity on the Internet, Routledge, NY.

Poster, Mark (1998) "Virtual Ethnicity: Tribal Identity in an Age of Global Communications", in Steve Jones (ed) Cybersociety 2.0, Thousand Oaks, Sage, 1998

Steinhorn, Leonard \& Diggs-Brown, Barbara (1999) By the Color of Our Skin: The Illusion of Integration and the Reality of Race, Dutton, NY.

Taylor, John (1989) Linguistic Categorization: Prototypes in Linguistic Theory, OUP.

Time Almanac 2006, Information Please, Boston 2005.

Turner, John., Hogg, M., Oaks, P., Reicher, S. \& Wetherall, M. (1988) Rediscovering the Social Group: A Self Categorization Theory, Blackwell, Oxford.

Van Knippenberg, D., Lossie, N. \& Wilke, H. (1994) "In-Group Prototypicality and Persuasion: Determinants of Heuristic and Systematic Message Processing", British Journal of Social Psychology, 33(3): 289-300.

Van den Berghe, Pierre L. (1997) "Rehabilitating Stereotypes" in Ethnic and Racial Studies, 20(1): 1-16. 